\title{
Evaluation as an organizational growth of a contemporary employee
}

\author{
Alice Magdalena Chițu (Soare), Brasov, Romania \\ Adelina Roxana Chițu, Ph.D, Brasov, Romania
}

\begin{abstract}
In order to survive and prosper, organizations need to respond in a timely and flexible way to change. Organizations are increasingly recognizing that the key to their success is largely contingent upon the capabilities of their employees-their human capital. In order to achieve the results expected regarding the human resource, a organization must have a training department, department that has to consider the need of training, to measure this need so that the management can take the necessary steps to improve the economical status of the organization.
\end{abstract}

\section{Keywords}

organization, training need, measurement, evaluation, people.

\section{JEL Codes: M 12, M 54}

The beginning of the second decade of the 21 st century, makes that the change remains an enduring theme. In order to survive and prosper, organizations in the private and the public sectors will need to respond in a timely and flexible way to social, technological, economic and political change. This means that a organization's survival and growth will depend on its ability to cope with the external and internal requirements that these changes will demand. This implies that existing and new staff will need to acquire new knowledge, skills, attitudes and perspectives on a continual basis.

Organizations are increasingly recognizing that the key to their success is largely contingent upon the capabilities of their employees - their human capital. Organizational performance is understandably dependent upon individual performance. As society moves toward increased emphasis on human rights, so organizations are moving toward sharper focus on developing the human potential.

Organization, in the current economic crisis, in order to survive, must invest in its main strength, namely people, but it can not be efficient in any other way than resorting to training-either with the help of the newly created department or the existing one, or by outsourcing this service.

Training can be described as a planned and systematic effort to modify or develop knowledge/skill/attitude through learning experience, to achieve effective performance in an activity or range of activities. Its purpose, in the work situation, is to enable an individual to acquire abilities in order that he or she can perform adequately a given task or job and realize their potential.

It has been seen that there are two major routes into training - the present/reactive route and future/proactive route. There are a number of methods, means and procedures associated with these routes which can help the trainer to investigate performance problems and to identify training and development needs. It is not possible to make a rigid classification because some of the methods could be used at more than one level depending on the nature of the performance problem or future need and on the size of the organization. 
About needs, as before irrespective of the route into training there should be a clear link between the needs which have been identified and corporate objectives. In reality such a level of sophistication is unlikely to exist in many organizations. Nevertheless, by adopting some of the approaches and through an understanding of the perspectives which have been described, trainers can make a positive contribution to organizational effectiveness even though their understanding of the corporate mission and objectives may not have been conveyed to them directly.

Furthermore, the trainer may be limited by a number of unforeseen or uncontrollable constraints which may not allow a fully comprehensive study of behavioral problems or training needs to be undertaken. In circumstances such as these, the trainer may have to employ very basic methodology and take a number of short cuts that may not be very satisfying.

However, there are many situations when a series of swift, professionally conducted interviews is all that is needed to find the critical issues and needs. Success on short projects that have an impact can gain a considerable amount of credibility for the trainer which can be put to good use when asking for more time and resources for other projects. Trainers should not always be prepared to give in to the 'quick and dirty' approach. Whatever the outcome of training projects, the trainers are accountable at all levels of their involvement; memories are short when it comes to remembering success and trainers are quick and easy targets when it comes to directing blame. It is not unrealistic to recommend that trainers should be responsible for familiarizing senior managers with the tools of the trainer's trade.

The ability to recognize the systems and subsystems of an organization is an important element in all training and development activities. Training and development exists to promote individual and organizational excellence by providing opportunities to develop workplace skills. The design and implementation of effecting training interventions cannot be accomplished without first identifying the various processes operating within the system.

One way of looking at it is to envision training as the subsystem that acquaints the people with the material and the technology. It helps them learn how to use the material in an approved fashion that allows the organization to reach its desired output. Because growth and change are inherent in organizations, they create a plethora of training needs. The term "learning organization" has become a popular buzzword to describe the way organizations must cope with their dynamic nature. A learning organization is based upon the principle of continuous learning, or a systematic method designed to increase learning within an organization, thereby enabling a more effective response to organizational change.

Learning organizations emphasize the importance of learning at the individual, team, and organizational levels, thereby increasing the likelihood of further developing a competent and competitive workforce. Peter Senge defines the term as an organization that is "continually expanding its capacity to create it's future." Doing so requires that individuals improve existing skills as well as learn new skills. Collectively, these newly acquired or refined skills can accomplish shared organizational goals. And, by anticipating future changes and working toward the knowledge and skills necessary to meet the demands resulting from these changes, the organization can systematically expand its capacity.

Able people may grow to a point where they are ready for responsibilities beyond their initial assignments. When this happens, the organization can profitably help them develop new, larger capabilities.

Training has become concerned not only with helping individuals to fill their positions adequately but also with helping entire organizations and subdepartments to grow and develop. Thus the title has changed from "Training and Development" to titles reflecting missions such as "Employee Development," "Organization Development," or "Human Resource Development."

This trend makes it wise for us to look a bit more closely at the interrelationship of the four inputs: people, technology, materials, and time. 
Training and development, though primarily concerned with people, is also concerned with technology and processes, or the precise way an organization does business. To accomplish the desired final output, an organization requires work. That work is divided among positions; and positions are divided into tasks - and tasks are assigned to people.

And there we have our second input: people! To perform their assigned tasks properly, all workers need to master and apply the unique technology governing their tasks. So here's where training enters the picture.

Civilization has not yet found the way to conceive and run an employee-free organization. Nor has it found a magic technology-and-skill potion that can be injected into people. Training is concerned primarily with the meeting of two inputs to organizational effectiveness: people and technology. Since organizations can rarely find people who are, at the time of employment, total masters of the unique requirements for specific jobs, organizations need a subsystem called "training" to help new employees master the technology of their tasks. Training changes uninformed employees into informed employees; training changes unskilled or semiskilled workers into employees who can perform their assigned tasks in the way the organization wants them done; employees become workers who do things "the right way."

This "right way" is called a standard - and one major function of training is to produce people who do their work "at standard." In fact, one simple way to envision how training contributes is to look at the steps by which people control their positions:

Step 1. Define the right (or standard) way for performing all the tasks needed by the organization.

Step 2. Secure people to perform these tasks.

Step 3. Find out how much of the task they can already perform. (What is their "inventory" of the necessary technology?)

Step 4. Train them to meet skill gaps - the difference in what they cannot already do and the standard for performing the task.

Step 5. Test them to make certain they can perform their assigned tasks to minimum standards.

Step 6. Give them the resources necessary to perform their tasks.

From that six-step process, we can also identify the two remaining inputs: time and material. People can't be miracle workers who create something from nothing. Management usually makes some statement about quality; it specifies what the finished product must look like; management also sets quantity standards. The job of the training department is to "output" people who can meet those standards, both in quality and quantity.

This description may imply that all training takes place after people are hired but before they are assigned to their jobs. That's obviously not true. Just look at the rosters of training programs and you'll see the names of lots of old-timers.

One legitimate reason for including old-timers in training programs is that the organization has undergone a major change such as equipment changes, processes change, policies change, and procedures change. Thus, veteran employees and new employees alike need training initiatives and benefit from them. When change occurs, an organization will have incumbent workers who no longer know how to do their jobs the new, right way. When people do not know how to do their jobs the right way, there is a training need. People do not usually know how to do the "next job" properly. Thus transfers, or the promotions implied in some career-planning designs, imply potential education needs. Some organizations have training departments that help prepare for the future.

But sometimes we find people in training programs even when the technology hasn't changed, or even when they aren't preparing for new responsibilities. Training is a remedy for people who do not know how - not for people who do know how but for one reason or another are no longer doing it. These other problems are performance problems - but they are not truly training problems; therefore, training is not an appropriate solution. 
The function once known as "training" has had to expand its own technology, strategies, and methodologies. Organizations get outputs because people perform tasks to a desired standard. Before people can perform their tasks properly, they must master the special technology used by the organization.

Training is the acquisition of the technology which permits employees to perform to standard. Thus training may be defined as an experience, a discipline, or a regimen that causes people to acquire new, predetermined behaviors.

Whenever employees need new behaviors, then we need a training department. But as we have already noted, training departments do more than merely fill the gaps in peoples' repertoires for carrying out assigned tasks; training specialists are also now involved in career development: developing people for "the next job," for retirement, and for their roles in society outside the employing organization.

One can never consider training if there was not an assessment regarding training needs. Even if a training activity has almost always a good result upon the people it has acted, it is a costly action than diminishes the profit of an organization.

The need itself can not be explained in other way than by thinking that it is helpful to consider two classes of training needs: individual and organizational. The difference is very simple, but it has heavy impact on the response made by the Training department. Of course, an individual training need exists for just one person, or for a very small population. Organizational training needs exist in a large group of employees such as the entire population with the same job classification. That happens, for example, when all clerks must be trained in a new procedure, or all managers in new policy. A manager in a specialized department, however, may develop an individual training need when some new technology is introduced into that field, or when performance as a manager reveals the noncomprehension of one facet of good managerial practice.

When new employees enter the organization, it is assumed that they know nothing of policies and procedures, nothing about organizational goals or structures. These deficiencies of knowledge are assumed to apply to all new people.

However, there may also be individual needs involving special tasks the newcomer will perform; it is a good idea to "take inventory" to see whether the individual meets the standards for some of the skills necessary to the satisfactory performance of a position.

Because there may be serious lapses in such areas, some organizations use "certification testing." These might be written exams, performance demonstrations, or both. They are tests requiring the employees to demonstrate their capabilities to perform a specific task or job duty.

One Training manager describes the process for certification testing this way: "They are used as predictors of job performance to assure the company that employees are ready to perform job responsibilities safely and accurately following the completion of their training." In other words, there is individual testing or assessment before there is organizational assessment.

It must be quite apparent that the Training manager has many sources of data about potential training needs. Training managers keep their eyes on the operation, on key communications, and on personnel moves even as they poll their client population.

If there are lots of signals from lots of sources, the training needs (or the need for some performance-problem solution) may exceed the resources available to meet those needs. At such moments, a written policy statement comes in mighty handy. But on what basis does that policy rest? In most organizations, at least four criteria must be considered: costeffectiveness, legal requirements, executive pressure, and the population to be served.

The cost of a performance problem can usually be determined. It's relatively easy if one immediately knows the cost of a defective unit. For either the deficiency or the undecided grievances, it's then necessary to compute the cost of the solution: development costs, salary costs, special expenses.

A second criterion is the legal requirement. Numerous government statutes dictate some of the decisions about what training to offer, like equal-employment legislation, occupational 
safety and health acts. It may be necessary to introduce programs for which no immediate tangible cost saving can be computed-it's the law.

Executive pressure is a third criterion. It usually comes from within the organization - and it's a criterion that smart training managers do not ignore. When Training managers complain that they don't get support from the top, they should ask themselves how many suggestions from chief executive managers, vicepresidents, or directors they turned down recently-or even in recent years.

Finally, there is the criterion of population. Sometimes this means simply that training goes to the most extensive problem. Macro needs may take priority over individual needs. Fortunately, it doesn't always need to work that way. The factor of influence and impact must also enter the decision table. Possibly the people who perform defectively occupy positions that affect the entire operations - for example, senior managers.

Performance problems that affect many workers, that are costly, that are related to the law, or that interest executives - all these deserve attention. Actual or potential knowledge deficiencies (DK) deserve training. Problems stemming from lack of practice (DP) should produce drill, or enforced on-the-job application. Problems stemming from other causes are probably deficiencies of execution (DE) and nontraining solutions are in order.

The Human Resources Department has in the job description to determine the need of training in an organization. This action it is not taken lightly, considering the effort it is needed to maintain such an activity- here we refer to financial cost, time spent, people involvement. In order to realize an efficient activity determining training needs, the organization can apply one or more different formulas to obtain the results needed. We can not state that we know all the formulas that might be used in determining that factor, but we can suggest an easier way to determine it, so that every organization, regardless of it's growth, can use it.

Even if we are used to consider that not all information from different cultures are applicable in our country, we consider that in this particular matter it is not the case.

Skill in writing performance standards, or at least in describing human behavior, is a "must" for all Training managers and specialists. Some organizations have begun to train managers from all departments in how to define performance standards. One such firm (Kemper Insurance Companies) has conducted workshops so that line managers become trainers for workshops at which still other line managers learn how to develop standards for their subordinates.

Kemper stresses the importance of developing the actual standards as a joint effort between the manager and the subordinate - not as a product of staff trainers. Once the standards are agreed upon by key people in the client department, the Training specialist is ready to ask that all-important question: "Do the people who must meet these standards possess the knowledge and skill to do so right now?" If the answer is yes, no training is indicated.

For newcomers, that seldom happens. They rarely know how to do their new jobs perfectly. For them, we have discovered a training need. It does not follow, however, that newcomers need training in all facets of their positions. Even newcomers have some ability and some knowledge, and we call this their "inventory." If we match the inventory against the standard we have set, we have a possible training need.

What the employee must do to meet the standard can be represented by the letter $\mathrm{M}$ for minimum mastery, or "must do." From this M we subtract the inventory to discover what the newcomer needs to learn to perform properly.

The test is somewhat different for employees who are already incumbent in their positions. We can again let $\mathrm{M}$ represent what the worker must do; from that we still subtract the $I$, or inventory. But this time the inventory is what the worker is actually doing now. The difference between the $\mathrm{M}$ and the $\mathrm{I}$ is a potential training need. We now have a formula for potential training needs:

$\mathrm{M}-\mathrm{I}=\mathrm{A}$ potential training need. 
The word "potential" is accurate. Why? Because with incumbents we are not yet certain that the reason for difference is lack of knowledge or skill. We don't yet know that they do not know how. Only if the reason for the difference is their not knowing how do we have a training need.

It's helpful to regard the distance between the "must do" and the "is doing" as a deficiency. We can put this into our formula by assigning it the letter D.

Now our formula looks like this:

$M-I=D$.

At this stage we are now ready to consider several different types of deficiency. When employees don't know how, we call this DK for "deficiency of knowledge." All DK's are regarded as training needs. If the difference between the "must do" and the "is doing" stems from other causes, we consider it a "deficiency of execution" and call it a DE. What "other causes" might there be? To name a few: lack of feedback, badly engineered jobs, or punishing consequences. DE's are not solvable through training.

Sometimes people know how to do the job, but have so little practice that they cannot maintain a satisfactory level of performance. This might be called a DP, or "deficiency of practice;" training in the form of drill may solve DP problems.

As we have often noted, there is no sense in training people to do what they can already do. Training is an appropriate solution to job-related problems for people who have what we call DK (deficiency of knowledge) or DP (deficiency of practice), both of which cause performance problems and deficiencies in knowledge, skills, or abilities. Feedback systems are attractive alternatives to training because they motivate workers, are inexpensive, and can be part of the regular management reporting system. First, let's see why feedback is in itself something of a motivator. When employees are able to see their own accomplishments, they have more reason to be interested in their work, more reason to be satisfied with their assignments, a greater sense of being needed, and a keener awareness of their contributions. Motivation is a fundamental component of performance. Supervisors and managers are responsible for achieving the goals of the organization through leading the performance or efforts of their employees.

Individual job performance can be summarized as follows:

Performance $=$ Ability $\times$ Motivation (effort)

In this model, performance is the product of ability times motivation:

Ability $=$ Aptitude $\mathrm{x}$ Training $\mathrm{x}$ Resources

- Aptitude refers to current skills and capabilities, education, and previous job experience.

- Resources are the tools that an employee needs to do the work (e.g., equipment, supplies, the work of other employees, time to complete the tasks, etc.).

Motivation $=$ Desire $\mathrm{x}$ Commitment

- Desire means wanting to perform the job, but desire by itself is not enough. An employee who wants to complete a task but who is easily distracted or discouraged cannot perform well (high desire/low commitment).

- Commitment means being persistent or trying hard to complete a task. However, without desire, an employee could be committed to his/her work but proceed slowly and produce only adequate results (low desire/high commitment). 
The multiplication symbol (x) demonstrates that all elements are essential. Someone with 100 percent of the motivation and 75 percent of the ability needed for a job can perform at above average level. However, an individual with only 10 percent of the ability would not be able to perform acceptably regardless of how motivated he or she is.

By finding out the need of training, one can say that the first step is finished: it follows the hard part consisting in TRAINING. Such an activity can be seen very different, depending on the people to be trained - here we must think of their number, age, education level -, the trainers - their personality, state of mind, knowledge regarding the object of training, all these can be disregarded if an organization prefers to collaborate with a specialized company in delivering training- and not finally the type of information they will have to know at the end of the course.

This part, even it is mostly considered as the hard part in a training process, will not be here in question given the extent of the subject. We will try to give to an entrepreneur the possibility to take the matter in his own hands in order to measure the training need but also the effect: alpha and omega.

Measurement has some other effects, too. The very process of measuring tends to increase the use of the new behaviors. There is an old adage that says, "In organizations, what is important gets measured" and its corollary, "What's measured, becomes important."

If any, one element is more important than others in effective measurement, it is selecting the proper thing to count. There's a significant dilemma there. If measurement doesn't count, if it isn't quantitative, then it isn't really measurement. If it counts the wrong things, it is an inappropriate measurement.

First, when we measure training achievements, the things we count should represent what we are seeking. That's true whether we measure perceptions, learning, or performance units. Next, those things should be inherently valuable. Finally, the search itself should develop an increasingly satisfactory performance of those inherently valuable units.

The thrust of effective evaluation is to make responsible judgments about important questions. If an improved operation is what the Training department wants to contribute, the inquiry must focus on hard data - and the evaluation must indicate whether or not the problem has been eliminated or significantly diminished. It breaks down into these steps:

1. Identify an unbearably deficient performance.

2. Identify specific units that characterize the problem.

3. Count the number of unacceptable units to establish a baseline.

4. Establish quantitative goals - a post-program baseline objective.

5. Conduct the change program.

6. Count the satisfactory and unsatisfactory units after the program.

7. Evaluate. Is the number of satisfactory units equal to the objective established in step 4? In other words, did the program produce the desired results?

If the production of new behaviors is the extent of the Training purpose, the evaluation will focus on the demonstrated acquisition and the perseverance of those behaviors. The successive steps are:

1. Establish the performance (learning) objectives.

2. Establish a desired achievement quota (the number of trainees divided into the number of behaviors acquired successfully).

3. Conduct the training or install the change program.

4. Test each trainee over each learning objective.

5. Compute the actual achievement quota.

6. Evaluate. Does the actual achievement quota equal or surpass the desired achievement quota?

When the mere acquisition isn't what the department wants to evaluate, there are additional steps to evaluate the on-the-job application of the new behaviors:

- Wait until a predetermined time and retest the graduates on each of the learning objectives. 
- Compute the application quota: Divide the number of successful demonstrations by the number of graduates.

- Evaluate. Do the retentions of the new behavior equal the goals established? T\&D officers who want to be relevant and accountable seek the hardest possible data from the widest possible range of representative sources.

The purpose of training is to change employees: their behavior, opinions, knowledge, or level of skill. The purpose of evaluation is to determine whether the objective was met and whether these changes have taken place. One way to consider the importance of evaluations is to recognize the feedback it provides. Feedback can be obtained through self-reporting or by observing the learner.

Various kinds of evaluations provide feedback to different people such as:

-Employees regarding their success in mastering new knowledge, attitudes, and skills.

-Employees concerning their work-related strengths and weaknesses. Evaluation results can be a source of positive reinforcement and an incentive for motivation

- Trainers for developing future interventions and program needs or creating modifications in the current training efforts.

-Supervisors as to whether there is observable change in employees effectiveness or performance as a result of participating in the training program.

- The organization regarding return on investment in training.

The world of work continues to become more and more complex and for everyone, including trainers, there are many learning curves ahead. The demands inferred by Senge (1990), 'As the world becomes more interconnected and business becomes more complex and dynamic, work must become more learningful', indicate that there will be a crucial and demanding role for training in the future.

There are many techniques, approaches and theories which can be applied in training and no single volume can do justice to them all. What we have done here was an attempt successfully we hope - to draw attention in one of the most important part of an organization, and that is: TRAINING.

\section{References}

1. Biech, E., (2005), Training for Dummies, Wiley Publishing Inc., Indianapolis, Indiana

2. Bray, T., (2009), The training design manual, Second Edition, Kogan Page, Philadelphia

3. Buckley, R., Caple, J., (2009), The theory \& practice of training, Sixth Edition, Kogan Page, Philadelphia

4. Dugan, L. (2003), Approaches to Training and Development, Third Edition, Perseus Publishing, Cambridge.

5. Mackey, D., Thorne, K., (2003), Everything You Ever Needed to Know about Training, Third Edition, Kogan Page Limited, London

6. Senge, P (1990), The Fifth Discipline, Doubleday, New York. 